
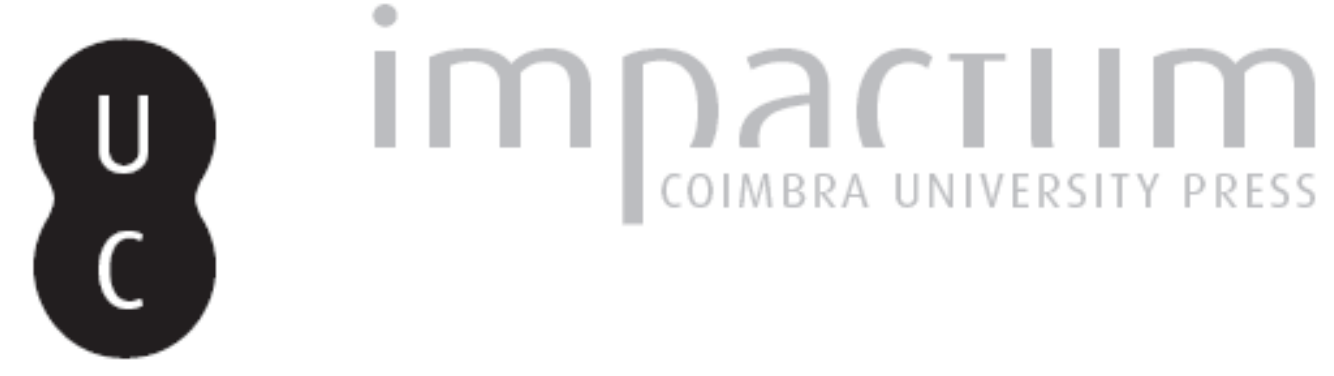

\title{
Os direitos humanos do idoso e as nuances protetivas no ordenamento jurídico brasileiro: uma abordagem acerca da (des)necessidade do estatuto do idoso
}

Autor(es): Rostelato, Telma Aparecida

Publicado por: Universidade Católica de Petrópolis

URL persistente:

URI:http://hdl.handle.net/10316.2/33783

DOI:

DOI:http://dx.doi.org/10.14195/2175-0947_3-2_6

Accessed : $\quad$ 26-Apr-2023 12:11:56

A navegação consulta e descarregamento dos títulos inseridos nas Bibliotecas Digitais UC Digitalis, UC Pombalina e UC Impactum, pressupõem a aceitação plena e sem reservas dos Termos e Condições de Uso destas Bibliotecas Digitais, disponíveis em https://digitalis.uc.pt/pt-pt/termos.

Conforme exposto nos referidos Termos e Condições de Uso, o descarregamento de títulos de acesso restrito requer uma licença válida de autorização devendo o utilizador aceder ao(s) documento(s) a partir de um endereço de IP da instituição detentora da supramencionada licença.

Ao utilizador é apenas permitido o descarregamento para uso pessoal, pelo que o emprego do(s) título(s) descarregado(s) para outro fim, designadamente comercial, carece de autorização do respetivo autor ou editor da obra.

Na medida em que todas as obras da UC Digitalis se encontram protegidas pelo Código do Direito de Autor e Direitos Conexos e demais legislação aplicável, toda a cópia, parcial ou total, deste documento, nos casos em que é legalmente admitida, deverá conter ou fazer-se acompanhar por este aviso.

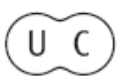



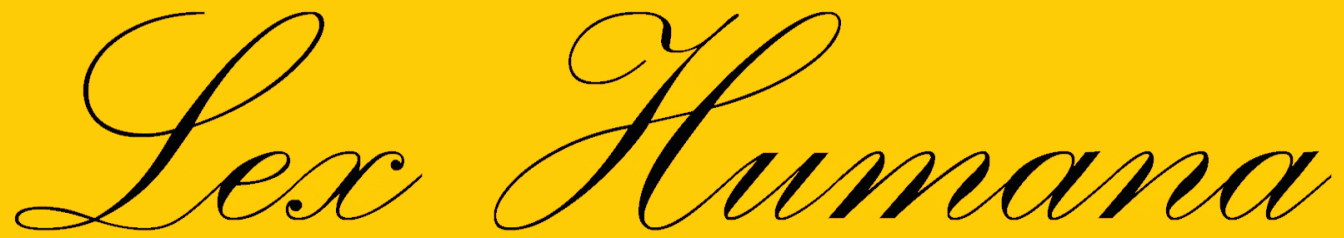

Revista do Programa de Pós-Graduação em Direito da UCP

ISSN(e) 2175-0947

Universidade Católica de Petrópolis Rua Benjamin Constant, 213 - Petrópolis - Centro CEP 25610-130

Tel: (24) 2244-4000 E-mail: lexhumana@ucp.br 


\title{
Os DIREITOS HUMANOS DO IDOSO E AS NUANCES PROTETIVAS NO ORDENAMENTO JURÍDICO BRASILEIRO: UMA ABORDAGEM ACERCA DA (DES)NECESSIDADE DO ESTATUTO DO IDOSO ${ }^{1}$
}

\author{
Telma Aparecida Rostelato
}

Resumo: O presente artigo ocupa-se em estudar as disposiçóes constitucionais que salvaguardam os direitos dos idosos no Brasil, cuja origem se deu em decorrência da preocupação em âmbito internacional, posto que elevado à categoria dos Direitos Humanos, o respeito a esta categoria de pessoas. Assim, uma vez constante em legislação específica, qual seja: o Estatuto do Idoso, o Estado brasileiro conta com um grandioso e expressivo painel protetivo dos idosos, que é o próprio texto constitucional, ora por gizar o dever estatal, num capítulo próprio, ora porque através dos princípios constitucionais da dignidade humana e do bem estar (princípio constitucional implícito), pode-se erigir o tratamento de cláusula pétrea ao ato de bem cuidar destas pessoas, significando que nada pode condicionar, restringir ou imiscuir o aludido direito daqueles, sob pena de afrontar o direito à existência digna dos mesmos, competindo a todos (família, sociedade e Estado) envidar esforços para evitar que tal infortúnio se implemente, intensificando-se dia a dia este amparo.

Palavras-Chave: Idoso; Dignidade da Pessoa Humana; Bem Estar; Dever Estatal.

\begin{abstract}
This article is concerned with studying the constitutional provisions that protect the rights of the elderly in Brazil, whose origin is given as a result of international concern, since the status of a human rights, respect to this category of people. So, once constant specific legislation, namely, the Elderly Statute, the Brazilian state has a grand and impressive protective panel of the elderly, which is the constitutional text itself, sometimes by the duty chalk state, a separate chapter, now because through the constitutional principles of human dignity and well-being (implicit constitutional principle), one can erect the treatment of entrenchment clause of the act and care for them, meaning that nothing can limit, restrict or interfere alluded to the rights of those under sorry to face the right to a decent of them, racing all (family, society and state) efforts to prevent such misfortune is implemented, increasing from day to day support this.
\end{abstract}

Keywords: Elderly; Dignity of the Human Person; Welfare; State Duty.

\footnotetext{
${ }^{1}$ Artigo recebido em 12/10/2011 e aprovado para publicação pelo Conselho Editorial em 02/12/2011.

2 Mestre em Direito pela Instituição Toledo de Ensino, ITE, Brasil. Currículo Lattes: http://lattes.cnpq.br/

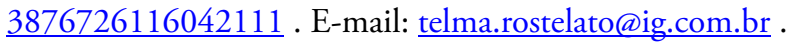




\section{INTRODUÇÃO}

Refletir acerca dos direitos dos idosos é tarefa necessária, embora constitua-se uma árdua missão, posto que inúmeras são as dificuldades que se implementam para a efetivaçáo deste desiderato, diuturnamente.

O mais elucidativo é que todos, de uma forma ou de outra, estão em constante contato com tal problemática, pois ainda que não se encontre enquadrado, como sendo pessoa idosa, segundo a definiçáo traçada pelo Estatuto do Idoso, invariavelmente tem-se um ente familiar que está próximo, ou mesmo uma pessoa com quem se mantêm laços de amizade.

Por estas razóes, objetiva-se descortinar neste estudo, uma aprofundada análise acerca da proteçáo constitucional contemplada a esta categoria de pessoas, por meio de princípios, perpassando sobre o princípio da dignidade da pessoa humana, táo caro ao ordenamento jurídico brasileiro, por manifestar-se viga mestra do arcabouço jurídico brasileiro.

Ainda, não passará despercebido o princípio constitucional implícito, do bem estar, uma vez sendo certo que recorrendo à interpretação sistemática, pode-se inferir que o citado princípio abarca igualmente, a significância da dispensa de cuidados adequados às pessoas idosas, vislumbrando o alcance da existência digna, clamada por todos, indistintamente, idosos ou não, porque a proteção direciona-se ao "eu" do ser humano, não permitindo deparar-se com restriçôes.

Nas conclusóes a serem tecidas, a autora propóe-se a discorrer acerca do alargamento desta proteção, que por ser compreendida como Direito Fundamental, encontra por consequência, salvaguarda internacional, através dos nominados Direitos Humanos.

\section{PROTEÇÃO DO IDOSO: PREMISSAS NECESSÁRIAS}

As pessoas idosas encontram larga proteção, nos dias atuais, ora por disposição constitucional expressa (no capítulo VII, do Título VIII, ladeando a Família, a Criança, o Adolescente e o Jovem), ora por lei específica (Estatuto do Idoso), perfilando para a ampla proteçáo em âmbito internacional, já que englobada está como sendo direito humano.

Sim, pois os Direitos Humanos comportam a significância de tratamento erigido, em âmbito internacional; ostentam um manto protetor internacional, dos Direitos Fundamentais, que são salvaguardados pelo direito interno brasileiro, através da Constituição Federal.

Portanto, ao se encontrarem protegidos sob espeque constitucional e em considerando-se a sua relevância, encontra guarida protetiva internacional, intitulado como sendo Direitos Humanos.

Por esta razão, recorrendo-nos das sábias palavras de José Afonso da Silva, acerca do tema, transcrevemos a seguir: 
Os idosos não foram esquecidos pelo constituinte. Ao contrário, vários dispositivos mencionam a velhice como objeto de direitos específicos, como o direito previdenciário (art. 201, I), o direito assistencial (art. 203, I), mas há dois dispositivos que merecem referência especial, porque o objeto de consideração é o homem em sua terceira idade. ${ }^{3}$

Assim, em atenção a reivindicaçóes sociais, o legislador preocupou-se em especificar pormenorizadamente os direitos das pessoas idosas, abordando a salvaguarda deste grupo de pessoas, sob diversos aspectos, em consideraçáo ao demasiado aumento da populaçáo idosa no nosso País, apontada em estatísticas efetuadas que:

(...) o envelhecimento populacional é uma realidade incontestável em todo mundo, sendo o brasileiro um dos mais acelerados, só comparável ao do México e Nigéria, e que até o ano de 2025 levará o Brasil a ocupar o $6^{\circ}$. Ou $5^{\circ}$. Lugar dentre os países de população idosa, passando da cifra de 14 milhóes de pessoas com 60 ou mais anos de idade para 33 ou 34 milhôes (...). ${ }^{4}$

Na seara infraconstitucional, a Lei no. 10.741, de 01 de outubro de 2003, mais conhecida como "Estatuto do Idoso", veio consolidar as disposiçóes da norma constitucional, servindo de bússola para os intérpretes do direito e em virtude de sua especificidade e minuciosidade, auxiliou também as pessoas leigas, com o que vem sendo afastada qualquer alegação de desconhecimento dos direitos das pessoas idosas, como elemento justificador do descumprimento destas normas protetivas, ensejadoras de discriminaçáo e desrespeito.

Da mesma forma que a Constituição Federal preceitua em seu artigo 230, em palavras similares, com intuito paralelo, o Estatuto do Idoso, em seu artigo $3^{\circ}$., determina a obrigação do Estado, da comunidade e da sociedade, além da família, para o zelo das pessoas idosas, de maneira a alcançar a efetivação de seus direitos, "in verbis":

Art. 3o É obrigação da família, da comunidade, da sociedade e do Poder Público assegurar ao idoso, com absoluta prioridade, a efetivaçáo do direito à vida, à saúde, à alimentação, à educaçáo, à cultura, ao esporte, ao lazer, ao trabalho, à cidadania, à liberdade, à dignidade, ao respeito e à convivência familiar e comunitária.

\footnotetext{
${ }^{3}$ SILVA, José Afonso da. Curso de direito constitucional positivo. São Paulo: Editora Revista dos Tribunais, 1989, p. 710.

${ }^{4}$ PENTEADO, Jaques de Camargo.A família e a justiça penal. São Paulo: Editora Revista dos Tribunais, 1998, p. 125.
} 
Constitui-se responsabilidade social a proteção do idoso: todos em conjunto, devem envidar esforços para viabilizar que as pessoas idosas consigam desfrutar de momentos agradáveis e felizes, nos últimos dias de suas vidas. Todos seremos idosos um dia, se permanecermos vivos.

Esta é uma assertiva constitucional que integra as normas de eficácia plena, cuja definiçấo nos traz José Afonso da Silva ${ }^{5}$, como sendo as que, desde a entrada em vigor da Constituição, produzem todos os seus efeitos essenciais, isto porque o legislador constituinte criou uma normatividade suficiente, incidindo direta e imediatamente sobre a matéria que lhes constitui objeto.

Com isso, tais normas têm aplicabilidade imediata, direta e integral, não ficando à mercê da manifestaçáo infraconstitucional, por meio de seus representantes, para que se viabilize a aplicaçáo do preceito constitucional.

Logo, é de se ver que não haveria necessidade de se discorrer acerca dos direitos dos idosos, num Estatuto, posto que a Constituição já o fizera, pelo que, deveriam estar sendo efetivados aludidos direitos desta categoria de pessoas, desde a data do advento da Carta Constitucional vigente, dispensando-se minúcias infraconstitucionais, pondere-se que náo se justifica o respeito aos idosos, em decorrência das exigências constitucionais, mas sim, em virtude do Estatuto do Idoso, como se de menor importância fosse a Constituição Federal, que se constitui nada mais, que o alicerce do ordenamento jurídico brasileiro.

E, uma vez sendo a base, esta poderia simplesmente ter sua interpretação estendida, a fim de realçar-lhe a proteçáo conferida aos intitulados Direitos Fundamentais, que transcendem o território nacional, conferindo-lhe o real tratamento outorgado aos direitos humanos, pois é inolvidável que são englobadas na seara de proteçáo internacional, as pessoas idosas.

Os direitos dos idosos englobados encontram-se no rol dos Direitos Fundamentais, disto não há que se olvidar, e daí estar-se-ia a um passo, de considerá-los como sendo abrangidos, pelos Direitos Humanos, seria apenas uma questão de compreender a significância da Constituiçáo Federal e por óbvio, dos enunciados nela encerrados, que não se careceria de um Estatuto...

\section{PREVISÃO CONSTITUCIONAL - SUMÁRIA ABORDAGEM}

\subsection{O princípio da dignidade humana}

A proteçáo constitucional do idoso encontra ampla sustentaçáo no princípio da dignidade da pessoa humana, estabelecido no art. $1^{\circ}$., inciso III, que permeia o nosso ordenamento, visando fixar precisas orientaçóes para a aplicaçấo e interpretaçáo dos demais princípios e direitos, protegidos na Carta Magna, quer de forma explícita ou não.

\footnotetext{
${ }^{5}$ SILVA, José Afonso da. Aplicabilidade das normas constitucionais. 5a ed. São Paulo: Malheiros, 2001, p. 82-83.
} 
Pondere-se preliminarmente que, alguns princípios constitucionais são encontrados no texto constitucional e muitas vezes sem mesmo recorrer à mais acurada interpretação, consegue-se identificar os fins propugnados, qual o bem imediatamente tutelado através daquela norma, em outros casos é necessária a busca, através do processo hermenêutico, para que se possa compreender o real objetivo da norma consagrada, através dos princípios.

Normalmente as Constituiçóes em geral, possuem uma parte que trata dos princípios, onde se encontram resguardados os direitos e eventuais garantias (como é o caso do Art. $5^{\circ}$ da nossa Constituição, que consagra os princípios da igualdade, legalidade, propriedade, acesso à jurisdição e muitos outros) que se preocuparam os constituintes, quando de sua elaboração, podendo também encontrar-se estabelecido no preâmbulo (como é o caso do princípio da democracia).

Afora destes locais, por todo o texto constitucional encontramos princípios, cuja aplicabilidade muitas vezes é viabilizada, através do princípio da dignidade, que sob todos os ângulos de análise pode servir de fundamento para sedimentar a observância dos demais.

Da mesma maneira que os pais devem desdobrar-se para proteger os seus filhos, estes devem respeitar e proteger os seus pais, aliás constitui este, o quarto mandamento, entre os dez, do livro sagrado, qual seja "Honrar pai e mãe" sobre todas as coisas ${ }^{6}$.

No mesmo sentido, para os católicos, São Paulo lembra que aos pais incumbe cuidar dos filhos, sem atormentá-los e aos filhos zelar por seus pais na velhice.

Assim, verifica-se que, desde há muito tempo, antes mesmo de existir qualquer previsão em âmbito constitucional, busca-se preservar a família, estabelecendo-se premissas de observância do respeito ao próximo.

A aludida locução "respeito ao próximo" acaba por desaguar no denominado princípio constitucional da dignidade da pessoa humana.

Objetivando obedecer o princípio da igualdade (art. 5o., "caput" da Constituição Federal), toda e qualquer pessoa precisa ser respeitada, no decorrer de toda a sua vida. Logo, as pessoas que carecem de maior proteção, face a dificuldades para a integração social, não podem ser excluídas, encontrando-se abrangidas as pessoas idosas, portanto.

Os cuidados a serem dispensados às pessoas idosas devem mirar-se para a valorização do sentido da uniáo familiar. Aliás, se inexistisse resguardo aos direitos da pessoa idosa, estaria sendo autorizado que somente nos melhores anos de convivência, por efetivo gozo de estado de saúde e até mesmo discernimento mental, que os familiares estivessem presentes na vida destes idosos e quando não mais desfrutassem deste estado, estariam autorizados a rejeitá-los.

Verificamos no art. 229 da Constituição Federal, que consta: "Os pais têm o dever de assistir, criar e educar os filhos menores, e os filhos maiores têm o dever de ajudar e amparar os pais na velhice, carência ou enfermidade.”

E no Código Civil, em seu artigo 1.696, o direito à prestação recíproca de alimentos, entre pais e filhos. ${ }^{7}$

\footnotetext{
${ }^{6}$ Constitui um dos dez mandamentos da religião hebraica, preservada por Moisés.
} 
Assim, há obrigaçáo bilateral, de pais e filhos, cada um a seu tempo, para cuidar do outro, no decurso de suas vidas. É inadmissível que em momentos, que a pessoa mais precise, louve-se o seu abandono, trata-se além de proteção constitucional, de dever humanitário.

Transcende a órbita do direito interno, é direito internacionalmente protegido, por compreender Direito Humano.

Não obstante, faz-se necessária a confirmação, no âmbito interno, daquilo que é almejado pelos direitos humanos, mormente para a proteçáo da dignidade da pessoa humana, neste sentido, valemo-nos do escólio de André de Carvalho Ramos ${ }^{8}$, que assevera:

(...) Ora, a justificação dos direitos humanos está na vontade da lei e a vontade da lei é que fundamenta a preservaçáo dos direitos humanos. Tal evidente tautologia enfraquece a proteção dos direitos humanos, quando a lei for omissa ou mesmo contrária à dignidade humana.

E se a proteçáo da pessoa idosa adquiriu enfoque internacional, pretendido por todos os povos, não poderia deixar de se constituir dever também da sociedade e do Estado, atuação desta natureza, a qual encontra-se constitucionalmente estabelecida no art. 230, vejamos: "A família, a sociedade e o Estado têm o dever de amparar as pessoas idosas, assegurando sua participação na comunidade, defendendo sua dignidade e bem-estar e garantindo-lhes o direito à vida."

Estarrecedora é a análise conclusiva deste artigo, pois confirma-se a preservaçáo do direito à vida e a preservaçáo desta, é incumbência que recai sobre o Estado e a sociedade, tanto quanto aos entes familiares.

Os artigos $8^{\circ}$. e $9^{\circ}$. do Estatuto do Idoso, adiante transcritos, expressam respectivamente, que a velhice é direito personalíssimo e que, dentre outros bens, a vida do idoso há que ser protegida pelo Estado.

Art. 8o $\mathrm{O}$ envelhecimento é um direito personalíssimo e a sua proteção um direito social, nos termos desta Lei e da legislação vigente.

Art. 9o É obrigaçáo do Estado, garantir à pessoa idosa a proteção à vida e à saúde, mediante efetivaçáo de políticas sociais públicas que permitam um envelhecimento saudável e em condiçóes de dignidade.

No Estado Democrático de Direito, além de se proteger a vida, clama-se pela proteção da vida com dignidade.

\footnotetext{
${ }^{7}$ Art. 1.696- O direito à prestação de alimentos é recíproco entre pais e filhos, e extensivo a todos os ascendentes, recaindo a obrigaçáo nos mais próximos em grau, uns em falta de outros.

${ }^{8}$ RAMOS, André de Carvalho. Teoria Geral dos Direitos Humanos na ordem internacional. Prefácio de Fábio Konder Comparato. São Paulo: Renovar, 2005, p. 42.
} 
Desta assertiva, compreendemos que não condiz com o dever da família, deixar seus entes em entidades, asilos ou casas de repouso, por alegarem não terem tempo ou condiçôes psicológicas para cuidar dos mesmos.

Desditosamente, o que vem sendo constatado é que os deveres de solidariedade familiar vem sendo deixados de lado, hodiernamente.

Ora, sem desmerecer o trabalho dos profissionais que de maneira louvável desempenham seu afazeres nestes locais, é sabido que o calor humano vivenciado nos lares, aquele afeto que se vê no decorrer de toda a vida, não mais se fará presente, nos aludidos locais, e este sentimento de indiferença, rejeição e por fim, abandono, resulta, não raras vezes, no agravamento do estado de saúde destas pessoas idosas, inclusive o comprometimento de seu estado psíquico, por extremado abalo que sofrem, inolvidavelmente.

\section{2 princípio do bem estar}

O sentimento de carinho, atenção e afeto, dispensado pelos familiares, perfaz senão o mais importante, um dos principais fatores que contribuem pela sensação de bem-estar da pessoa humana, não sendo diferente, com relação às pessoas idosas.

Muito embora o princípio do bem estar constitua-se preceito constitucional implícito, vez que os princípios implícitos não o são simplesmente porque assim um determinado intérprete em isolado o pretendeu, mas sim decorre de um exame conjunto de todo o texto constitucional, devendo haver ainda, o apoio jurisprudencial, para que seja elevado à esta categoria, como considera Tupinambá Miguel Castro do Nascimento. ${ }^{9}$

Ao lado do princípio do bem estar, pode-se pontuar como exemplos, o princípio da razoabilidade, da proporcionalidade, do pluralismo social, da separação dos poderes (que embora conste como cláusula pétrea, não está expresso como princípio), motivação dos atos administrativos em geral, etc.

Assim, ainda que não constantes de forma expressa, eles referem-se aos fundamentos constitucionais expressamente consagrados, e que se contrariados acarretam a lesão aos fins propugnados pelo Estado Democrático de Direito, constante no Preâmbulo da nossa Constituição, portanto a sua relevância, atualmente considerada no nosso ordenamento.

Através da via hermenêutica pode-se chegar ao reconhecimento de princípios constitucionais implícitos, portanto, sendo o caso do bem estar.

Inolvidável que se consubstancia imensa dificuldade para muitos idosos, quando seus filhos os deixam num asilo ou outro ambiente congênere, lugar normalmente distante de seus lares, com hábitos alimentares, de higiene e horários, igualmente diferentes.

Ilustrativa e orientadora é a assertiva de Ives Gandra Martins:

\footnotetext{
${ }^{9}$ Comentários à Constituição Federal: Princípios Fundamentais - Arts. $1^{\circ}$ a $4^{\mathrm{o}}$. Porto Alegre: Livraria do Advogado, 1997, p. 90-91.
} 
(...) Manter o idoso em família e dar sentido a seus últimos anos é a melhor terapêutica, que inclusive beneficia também filhos e familiares, pois sentirão que venceram seu egoísmo e comodismo para dedicar uma parte de seu tempo e recursos àqueles que antes deles cuidaram. ${ }^{10}$

Ora, todo ser humano sofre com mudanças, o que dizer então, quando tais mudanças são-lhe impostas, num período em que se encontra adoecido, com suas forças esgarçadas e, ainda acrescido pelo fato de ser abandonado pelos seus entes queridos...

Interessante o que pondera Ives Gandra Martins, cujo trecho de sua obra transcrevemos:

No dia em que a família for valorizada e em que os pais se sentirem responsáveis pelos filhos, muitas vezes sacrificando-se num casamento difícil em vez de procurar a separação fácil, serão reconhecidos pelos filhos e terão uma velhice em que a solidariedade que demonstraram será recompensada por uma solidariedade com amor e dedicação, toda a sociedade se beneficiando dessa concepção de vida mais pura e mais sábia. ${ }^{11}$

Afirmamos então, que a base familiar é sumamente importante, o tratamento que os pais dispensam aos filhos também influencia e pode ser um dos fatores para o tratamento que estes filhos virão dispensar aos seus pais, na velhice.

São estes problemas que recaem sobre a instituição da família, que vem sofrendo abalos incontornáveis, os quais podem ser a motivação para o abandono, por parte dos filhos.

Importa destacar que, em algumas circunstâncias as pessoas idosas não têm familiares que possam prestar-lhes assistência, não restando outra alternativa senão manter-lhes em casas de repouso; incumbe ao Estado portanto, disponibilizar de estabelecimentos apropriados para o amparo destas pessoas idosas, conferindo-lhes tratamento digno.

Os programas de amparo aos idosos serão executados preferencialmente em seus lares, é o que preconiza o $\$ 1^{\circ}$. do art. 230 da Constituição Federal.

Por outro lado, compete à sociedade, como um todo, respeitar estas pessoas idosas, quer porque sempre terão uma em sua própria família, quer porque a Constituição lhe outorga este dever, ou simplesmente porque um dia também serão enquadrados como sendo pessoa idosa.

Ao lado, da família e do Estado, a sociedade compreende um dos três elementos que conformam uma Nação, logo ao Estado recai “a obrigação de amparar as pessoas idosas, que já deram sua contribuição à sociedade e estão aposentadas ou sem condiçóes de trabalhar." ${ }^{2}$

\footnotetext{
${ }^{10}$ BASTOS, Celso Ribeiro. Comentários à Constituição do Brasil: promulgada em 5 de outubro de 1988, 8o. Volume: arts. 193 a 232, comentado por Celso Ribeiro Bastos e Ives Gandra da Silva Martins. São Paulo, Saraiva, 2000, p. $1112-$ 3.

${ }^{11}$ Idem, p. 1107.

${ }^{12}$ Ibidem, p. 1109.
} 
A sociedade, que é traduzida como sendo o povo da Nação, deve por sua vez, auxiliar para que o Estado possa viabilizar meios aptos a fazer com que as pessoas idosas se sintam úteis em sua comunidade, isto significa inclusão.

A inclusão é um processo, como assevera Claudia Werneck que “(..) normalizar uma pessoa nâo significa torná-las normal. Significa dar a ela o direito de ser diferente e ter suas necessidades reconhecidas e atendidas pela sociedade. "13

Isto porque, nas palavras da eminente autora: "Incluir é abandonar estereótipos".

Aceitar que haja qualquer tratamento diferenciado às pessoas idosas, por parte de quem quer que seja, é aceitar a discriminação, ato atentatório a um dos objetivos fundamentais da República Federativa do Brasil (art. 3º., inciso IV da Constituição Federal), isto com a finalidade de promover o bem de todos.

$\mathrm{O}$ princípio da não-discriminação encontra-se resguardado no art. $3^{\circ}$., inciso IV da Constituição Federal, segundo o qual todo ser humano tem o direito de não ser discriminado, considerada a discriminação sob todos os aspectos.

Neste âmbito, é possível verificar que a discriminação não pode recair sobre qualquer pessoa humana; incluídas por óbvio, aquelas pessoas idosas. Assim, mesmo que inexista expressa menção no texto constitucional, alusivo ao princípio do bem estar, este está a ocupar um papel protetivo, logo é um princípio implícito, segundo depreende-se da leitura da obra de Fábio Gabos Alvares $^{14}$.

Desnecessário seria constar em textos constitucionais ou infraconstitucionais, o dever de bem tratar a pessoa humana (incluídas as pessoas idosas), resguardando a sua dignidade, já que estes são valores pessoais e deveriam compor o "eu” de cada um, pois se o que almejamos na vida é sermos felizes, seria suficiente as pessoas terem em mente que devem proporcionar meios para que nosso semelhante também o seja.

\section{CONCLUSÓES}

1) Os idosos brasileiros têm hodiernamente um Estatuto, que veio tratar de seus direitos, sendo demasiadamente interessante pensar-se que houve a necessidade de se contemplar numa legislação própria, de maneira minudenciada, os aspectos protetivos desta categoria de pessoas.

2) A aludida observância se faz, devido às expressas disposiçóes constitucionais, que abordam a temática, versando de um capítulo, ao lado da Família, da Criança, do Adolescente e

${ }^{13}$ WERNECK, Claudia. Ninguém mais vai ser bonzinho na sociedade inclusiva. 2a. ed., Rio de Janeiro: WVA, 2000, p. 52.

${ }^{14}$ ALVARES, Fábio Gabos. Os Princípios Constitucionais Implícitos. In: Revista do Instituto de Pesquisas e Estudos, no 38. Bauru: Instituição Toledo de Ensino de Bauru, set./dez. 2003, passim. 
do Jovem. Não obstante, causa-nos temor o fato de se necessitar frisar os direitos de uma ou outra categoria de pessoas, para que os mesmos se façam respeitar pela sociedade...

3) Não podemos esquecer que o ordenamento jurídico brasileiro não dispõe de um Estatuto da Família, nem de um Estatuto do Jovem (ainda que se encontre em trâmite Projeto de Lei, com este intuito). Não seria hipocrisia ou mesmo um singelo desrespeito ter-se que declarar minuciosamente, aquilo que a Carta Magna já o fez, tão magistralmente?

4) Não seria, na realidade, uma forma de se mascarar o descumprimento aos preceitos constitucionais, por exigir-se que legislação infraconstitucional venha regulamentar o que se trata de norma constitucional de eficácia plena?

5) Respeitar o próximo, garantindo o seu bem estar, independentemente de sua idade e conferir-lhe tratamento diferenciado, justamente em atenção ao preceito constitucional da isonomia, ostenta, no mínimo, o dever de cumprimento ao exercício da cidadania, anseio de todos os povos e Naçóes, por isso já tendo inclusive, sido elevada a temática à guarida internacional, em efetuando-se a análise da abrangência atribuída à significância dos Direitos Humanos. 


\section{Referências bibliográficas}

ALVARES, Fábio Gabos. Os Princípios Constitucionais Implícitos. In: Revista do Instituto de Pesquisas e Estudos, no 38. Bauru: Instituição Toledo de Ensino de Bauru, set./dez. 2003.

BASTOS, Celso Ribeiro. Comentários à Constituição do Brasil: promulgada em 5 de outubro de 1988, 80. Volume: arts. 193 a 232, comentado por Celso Ribeiro Bastos e Ives Gandra da Silva Martins. São Paulo, Saraiva, 2000.

DINIZ, Maria Helena. Norma constitucional e seus efeitos. 5ª ed. atual. São Paulo: Saraiva, 2001.

ESPÍNDOLA, Ruy Samuel. Conceito de Princípios Constitucionais. 2a ed. rev. atual. e aum. São Paulo: Revista dos Tribunais, 2002.

FERREIRA FILHO, Manoel Gonçalves. Direitos Humanos Fundamentais. São Paulo: Saraiva, 2000, $4^{\mathrm{a}}$. ed. revista.

KOSOVSKI, Ester. Minorias e discriminação: direito das minorias. Rio de Janeiro: Forense, 2001.

NASCIMENTO, Miguel Castro do. Comentários à Constituição Federal: Princípios Fundamentais - Arts. $1^{\circ}$ a $4^{o}$. Porto Alegre: Livraria do Advogado, 1997.

PENTEADO, Jaques de Camargo. A família e a justiça penal. São Paulo: Editora Revista dos Tribunais, 1998.

RAMOS, André de Carvalho. Teoria Geral dos Direitos Humanos na ordem internacional. Prefácio de Fábio Konder Comparato. São Paulo: Renovar, 2005.

ROSTELATO, Telma Aparecida; SILVA, Eduardo Jannone da. O idoso sob a ótica da proteção dos direitos fundamentais, “in”: Direitos Fundamentais: da normatização à efetividades nos 20 anos de Constituição Brasileira. Birigui: Boreal Editora, 2008.

ROTHENBURG, Walter Claudius. Princípios Constitucionais. Porto Alegre: Sergio Antonio Fabris Editor, 2003.

SILVA, José Afonso da. Curso de direito constitucional positivo. São Paulo: Editora Revista dos Tribunais, 1989. . Aplicabilidade das normas constitucionais. 5a ed. São Paulo: Malheiros, 2001. 
WERNECK, Claudia. Ninguém mais vai ser bonzinho na sociedade inclusiva. $2^{a}$. ed., Rio de Janeiro: WVA, 2000. 